\title{
Epidemiology of maternal death in a tertiary care centre
}

\author{
Pranjal Tamuli, Hemkanta Sarma, Abu Hasan Sarkar \\ Correspondence: Dr Abu Hasan Sarkar, Assistant Professor, Dept. of Community Medicine, \\ Tomo Riba Institute of Health and Medical Sciences (TRIHMS), Naharlagun, Arunachal \\ Pradesh; Email - abu_sarkar@yahoo.co.in
}

Distributed under Attribution-NonCommercial-ShareAlike 4.0 International (CC BY-NC-SA 4.0)

\begin{abstract}
Objectives: To estimate the maternal mortality rate and to study the related factors responsible for the maternal deaths during the period from 2011 to 2016. Materials and methods: The present study was a retrospective record based study carried out from maternal death registers and Maternal Death Review (MDR) forms. The live birth records were obtained from labour room registers. Results: The institutional MMR was calculated to be 468.18 per 1,00,000 live births. The most common age (mode) of death was seen among women of 20 years; with $92.2 \%$ of deaths among women of rural area and $55 \%$ deaths were recorded in the tea tribe community alone. Most (54.4\%) of the deaths were found amongst the primigravida. It was observed that $36.1 \%$ of the deaths occurred due to hypertensive disorder followed by haemorrhage $(20.6 \%)$ and sepsis $(10.6 \%)$. Anemia contributed $7.7 \%$ to the deaths and $1.7 \%$ was due to obstructed labor. Other causes included ruptured ectopic, ARDS, pulmonary embolism, DIC, rupture uterus. Conclusion: In the present study, many deaths have occurred due to hypertension, haemorrhagic and anaemic causes and many of them did not receive adequate antenatal attention.
\end{abstract}

Keywords: Maternal mortality rate, MMR, maternal death in Assam, ante natal care.

According to WHO, approximately 830 women die globally every day from preventable causes of maternal death. Amongst them, 99\% deaths occur in developing countries with $50 \%$ occurring in sub- Saharan Africa and approximately one third in South Asia. ${ }^{1}$ Maternal death is defined as death of a women while pregnant or within 42 days of termination of pregnancy, irrespective of the duration or site of pregnancy, from any cause related to or aggravated by the pregnancy or its management but not from accidental or incidental causes ${ }^{2}$. Maternal mortality ratio is defined as maternal death per 1,00,000 live births 2.

In India, attempt to reduce maternal death have been made way back since the British rule by establishment of "Dai" School in Amritsar in 1880. In 1902, first Midwifery act was passed in London. ${ }^{3-5}$ In 1997, RCH (Reproductive and Child Health) programme was launched to include additional elements like 24 hours delivery service at Primary Health Centre level, availability of local funds for referral transport, training of medical officers in obstetrical care and obstetrical anaesthesia ${ }^{5}$. The RCH programme entered into second phase in 2005 and was included in National Rural Health Mission (NRHM). NRHM was launched in a mission mode and was expected to achieve the goal set under National Health Policy 2002 and Millennium

Received: $27^{\text {th }}$ June 2018. Accepted: $22^{\text {nd }}$ December 2018.

Tamuli P, Sarma H, Sarkar AH. Epidemiology of maternal death in a tertiary care centre. The New Indian Journal of OBGYN. 2019; 5(2): 88-92 
The New Indian Journal of OBGYN. 2019 (January-June); 5(2)

Development Goals (MDG) of reducing maternal death to $100 / 1,00,000$ by the year 2012. But with MMR 167 by the year 2013, India remained far from achieving $\mathrm{MDG}^{5}$. In the year 2013 NRHM was restructured and renamed as National Health Mission (NHM) with the objective of reducing maternal death by $100 / 1,00,000$ by next five years. ${ }^{6}$

Sustainable Development Goals (SDG) was adopted by United Nations in September, 2015. The goal 3 of SDG is to "Ensure healthy lives and well being for all and at all ages. One of the targets to achieve this goal is to reduce maternal mortality to less than 70 per 100000 live births by $2030^{7}$.

In India the MMR (Maternal Mortality Ratio) is very high (130) and Assam has the highest (237) amongst the states as per the reports of SRS, 2014-16. ${ }^{4}$ Though death is an inevitable truth, most maternal deaths can be prevented with adequate antenatal, intranatal and postnatal care. ${ }^{1}$ Hence a clear understanding into the causes and factors related to maternal death is necessary. Local research may provide scientific information and help in formulation of community specific and problem specific solutions. Hence the present study was carried out with the following objectives.

Objectives -1 ) To estimate the maternal mortality rate in Jorhat Medical College and Hospital for the period from 2011 to 2016. 2) To study the factors related to the maternal deaths that occurred in Jorhat Medical College and Hospital from 2011 to 2016.

\section{Methodology}

The present study was a retrospective record based study carried out in Jorhat Medical College and Hospital. Permission from Hospital Authority was obtained for accessing the data. Hospital records of maternal death occurring in the institute from 2011 to 2016 were accessed from maternal death registers and Maternal Death Review (MDR) forms. Records of maternal deaths which were complete in all aspects were considered for this study and records with incomplete data were excluded after careful examination and attempt to retrieve. The live birth records were obtained from labour room registers. Collected data were analysed using EPI info version 7 for windows downloaded free from the website of CDC, Atlanta.

\section{Results}

The total number of live births from 2011 to 2016 was 38,874 and the number of maternal deaths was 182 . This makes the institutional MMR (Maternal Mortality Ratio) of 468.18 per 1,00,000 live births. Records of two cases could not be retrieved and hence further detailed analysis

Table 1: Demography of the maternal death cases

\begin{tabular}{llll}
\hline $\begin{array}{l}\text { Demographic } \\
\text { characteristics }\end{array}$ & $\begin{array}{l}\text { Number of } \\
\text { maternal } \\
\text { deaths }(\mathbf{n = 1 8 0})\end{array}$ & $\begin{array}{l}\text { Percentage } \\
\mathbf{( \% )}\end{array}$ \\
\hline Age in & $<18$ & 0 & 0 \\
years & 18 to 35 & 176 & 98.2 \\
& $>35$ & 4 & 1.8 \\
\hline Area of & Rural & 166 & 92.2 \\
residence & Urban & 14 & 7.8 \\
\hline \multirow{4}{*}{ Caste } & General & 32 & 17.8 \\
& OBC & 16 & 8.9 \\
& SC & 16 & 8.9 \\
& ST & 17 & 9.4 \\
& Tea tribe & 99 & 55 \\
\hline
\end{tabular}

was carried out on 180 cases. The mean age of all the deaths was $24.26 \pm 5$ years ranging from 18 years to 45 years of age. The most common age (mode) of death was seen among women of 20 years. In the current study, $92.2 \%$ of deaths occurred in women belonging to rural area and 55\% deaths were recorded in the tea tribe community alone (table 1$)$. Most (54.4\%) of the deaths were found amongst the primigravida. When the status of antenatal check-up was analysed, it was found that $37.2 \%$ women had atleast one antenatal check-up while an alarming $42.2 \%$ of the reported death cases did not receive any antenatal check-up (table 2). No data was available regarding the antenatal check-up of $20.6 \%$ cases. Many of the death cases $(45.6 \%)$ were referred to JMCH from other health care institutes. On analysis of time from admission to declaration of death, it was seen that most of the deaths $(37.2 \%)$ were occurred during the first two hours of admission and $66.1 \%$ of deaths occurred within the first day of admission as a whole. The second day had $14.4 \%$ deaths and $19.4 \%$ of deaths occurred thereafter (table 2). Abortion and ectopic pregnancy constituted $6 \%$ of deaths. This numbers could have been far below with adequate awareness on ectopic pregnancy and abortion. Post partum period was seen to be the most 
The New Indian Journal of OBGYN. 2019 (January-June); 5(2)

Vulnerable time as most of the deaths (56\%) were

Table 2: Pregnancy and delivery related characteristics

\begin{tabular}{llll}
\hline Variables & & $\begin{array}{l}\text { Number of maternal } \\
\text { deaths }(\mathbf{n}=\mathbf{1 8 0})\end{array}$ & $\begin{array}{l}\text { Percentage } \\
\mathbf{( \% )}\end{array}$ \\
\hline \multirow{3}{*}{ Gravida } & G1 & 98 & 54.4 \\
& G2 & 48 & 26.7 \\
& G3 & 15 & 8.3 \\
& $>$ G3 & 19 & 10.6 \\
\hline \multirow{3}{*}{ ANC status } & Done & 67 & 37.2 \\
& Not done & 76 & 42.2 \\
& Data not available & 37 & 20.6 \\
\hline \multirow{3}{*}{ Referred case } & Yes & 82 & 45.6 \\
& No & 87 & 48.3 \\
& Data not available & 11 & 6.1 \\
\hline \multirow{3}{*}{ Place of } & Tertiary centre & 100 & 55.6 \\
delivery & Primary/secondary & 17 & 9.4 \\
& Home & 12 & 6.7 \\
\hline Labour started & Yot applicable* & 51 & 28.3 \\
& No & 134 & 74.4 \\
\hline Interval from & $0-2$ & 46 & 25.6 \\
admission to & 2-12 & 21 & 11.7 \\
death (in & $13-24$ & 67 & 37.2 \\
hours) & $25-48$ & 31 & 17.2 \\
& $>48$ & 26 & 14.4 \\
\hline
\end{tabular}

*Not applicable means death during Ante natal, Intrapartum period or Abortion cases

occurred in this period (figure 1). It was observed that $36.1 \%$ of the deaths occurred due to hypertensive disorder followed by haemorrhage $(20.6 \%)$ and sepsis $(10.6 \%)$.

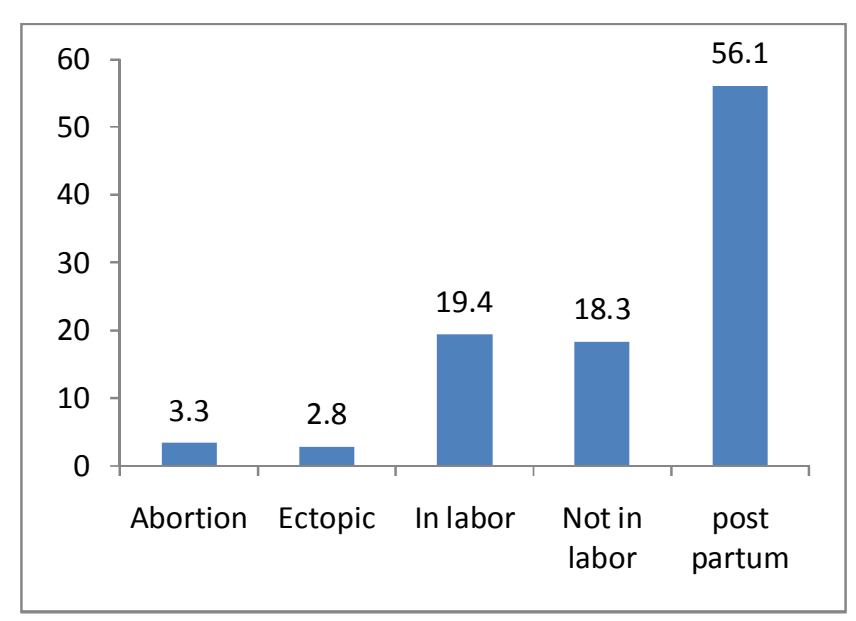

Figure 1: State of pregnancy while death has occurred
Anemia contributed $7.7 \%$ to the deaths and $1.7 \%$ was due to obstructed labor. Other causes included ruptured ectopic, ARDS, pulmonary embolism, DIC, rupture uterus (figure 2).

\section{Discussion}

In the present study there were 182 maternal deaths amongst 38,874 live births from 2011 to 2016 giving an institutional MMR of 468.18 per $1,00,000$ live birth. The MMR calculated from our study was much higher than the national and state average. This high MMR probably can be explained by the fact that the present study is being conducted in a tertiary care hospital which receives a large number of complicated referred cases from various government as well as private hospitals. The MMR calculated from our study was found to be consistent with a number of other studies conducted in tertiary care hospitals elsewhere in the country ${ }^{8,10}$.

In our study, $89.43 \%$ of maternal deaths were occurred in women belonging to rural areas which were very similar to results obtained by Shannon Fernandes et al where 78.6\% deaths were from rural areas ${ }^{9}$. In this study $55 \%$ deaths were recorded in the tea tribe community but another study conducted in Dibrugarh shows a higher percentage of $66.7 \%{ }^{11}$. In the present study $54.4 \%$ of

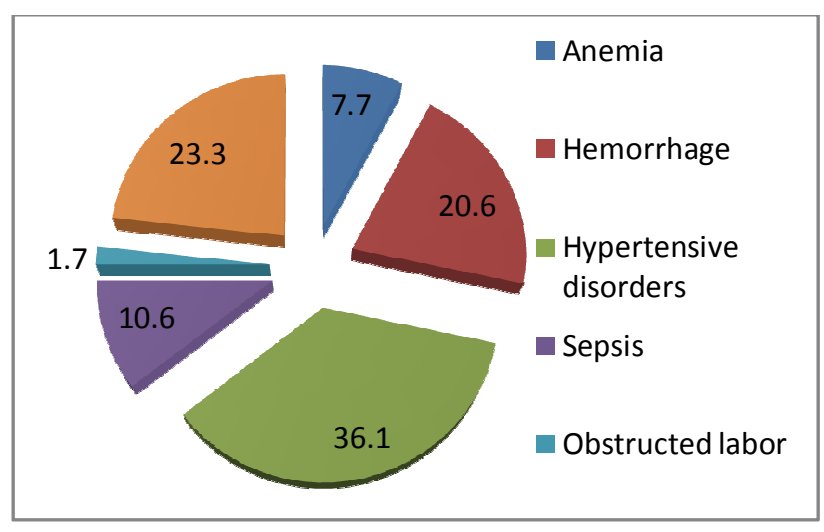

Figure 2: Distribution of maternal deaths according to causes $(n=180)$ 
deaths occurred in primigravida in contrast to many studies conducted elsewhere in the country which showed higher percentage of death amongst multigravida ${ }^{9-12}$.

In the present study $37.2 \%$ of deaths occurred during the first two hours of admission and $66.1 \%$ of deaths occurred within the first day of admission as a whole. The second day had $14.4 \%$ deaths and $19.4 \%$ deaths occurred thereafter. Vidyadhar et al reported $2.63 \%$ of deaths in first hour of admission and $15.79 \%$ death in 2 to 12 hour of admission ${ }^{10}$, within 24 hour $44.9 \%, 1^{\text {st }}$ day to $6^{\text {th }}$ day $42.6 \%$ and after 7 days of admission $12.5 \%{ }^{12}$. Priya et al. in their study also observed maximum deaths (54.63\%) within $24 \mathrm{hrs}$ of hospital admission ${ }^{13}$. In contrast, $47.20 \%$ maternal deaths were within 1-7 days and $27.07 \%$ were beyond 7 days of hospital admission in the study by Bhosale et al ${ }^{14}$.

It was observed that $36.1 \%$ of the deaths occurred due to hypertensive disorder followed by haemorrhage (20.6\%) and sepsis (10.6\%). Anemia contributed $7.7 \%$ to the deaths and $1.7 \%$ was due to obstructed labor. Other causes included ruptured ectopic, ARDS, pulmonary embolism, DIC, rupture uterus in smaller proportions. Archana et al reported $24.1 \%$ of deaths due to haemorrhage and $20.2 \%$ due to sepsis ${ }^{8}$. Ashraf et al reported of $24.82 \%$ deaths due to haemorrhage, $14.8 \%$ of deaths due to anaemia and $6.8 \%$ of deaths due to sepsis ${ }^{15}$. Uma et al reported $10.8 \%$ of deaths due to DIC, $5.4 \%$ of deaths due to pulmonary embolism, $8.1 \%$ of deaths due to rupture uterus ${ }^{16}$.

The study was a record based study carried out in a tertiary care hospital. Hence the findings of this study may not be generalized. Cases of maternal deaths at home or private health care facilities could have been considered. That would have reflected a larger picture. Also, incomplete hospital record posed as limitation to the study.

\section{Conclusion}

Approach to combat maternal death can be preventive, curative or a combination of both. In the present study, many deaths have occurred due to hypertension, haemorrhagic and anaemic causes and a great number of them did not receive adequate antenatal attention. Quality ante natal vigilance with adequate diagnosis and subsequent management might have prevented those cases from advancing to complications. It is important to diagnose at the earliest with timely referral to appropriate facility where quality curative care may be provided. This endeavour can be achieved by enhancing the quality of antenatal, intranatal and postnatal care. Ultimately, the picture reduces to the requirement of trained manpower in the periphery, awareness of people to act without delay, building up of adequate human resources and infrastructure. Repeated job training may be considered for the peripheral health workers. Further extensive research both quantitative and qualitative are required to build up an indepth insight and sound scientific understanding to tackle the problem of maternal mortality at local level.

\section{Conflict of interest: None. Disclaimer: Nil.}

\section{References}

1.WHO. Maternal mortality, Fact sheet $\mathrm{N}^{\circ} 348$ [Internet]. Geneva 27, Switzerland; 2014 [Updated November 2015; cited on 10th December 2015]. Available from: http://www.who. int/mediacentre/ factsheets/fs348/en/.

2.Park K. Park's Textbook of Preventive and Social Medicine. 23rd edition. Jabalpur: M/s Banarsidas. Bhanot Publishers; 2015.

3.United Nations. GOAL 5: Improve maternal health [Internet]. United Nations Headquarters, New York; 2015[ Cited on 10th December 2015]. Available from: http://www.un.org/millenniumgoals/maternal.shtml.

4.SRS. SRS bulletin. New Delhi: Vital statistics division; 2011. [Cited on 19th February 2016]. Available from:http://www.censusindia.gov.in/vital_statistics/mmr_bul letin_2011-13.pdf

5.Kumar S. Reducing Maternal Mortality in India: Policy, Equity, and Quality Issues. Indian Journal of Public Health. 2010; 54(2): 57-64.

6.Kishore J. National health programmes of India.11 th edition. New Delhi: Century Publications; 2014.

7.United Nations. Transforming our world: the 2030 Agenda for Sustainable Development [Internet]. United Nations Headquarters, New York; 2015[Cited on 10th December 2015]. Available from:

https://sustainabledevelopment.un.org/

8. Bhosale A, Qureshi S, Nandanwar S. Maternal Mortality at a Tertiary Institute : A five year study. Bombay Hospital Journal. 2011; 53( 2): 189-92. 
9.Fernandes S, Prabhu P, Cunha P. Maternal Mortality At A Tertiary Care Teaching Hospital in South India: 10 Year Retrospective Study. Int J Med Health Sci. 2015; 4(3): 32731 .

10.Vidhyadhar B, Purushottam G, Garg R. Maternal mortality at a tertiary care teaching hospital of rural India, a retrospective study. Int J Biol Med Res. 2011; 2(4):1043- 6.

11.Hazarika L, Phukan P, Sharma A, Das NK. Maternal mortality at a tertiary care teaching hospital in Dibrugarh district, Assam: a retrospective study. Int J Community Med Public Health. 2017 Sep; 4(9): 3342-46

12.Nair A, Doibale MK, Gujrathi VV, Inamdar IF, Shingare AD, Rajput PS. Study of maternal mortality in a tertiary care hospital in a district of Maharashtra. IJMSPH. 2016; 5(9):1851-54

13.Priya N, Verma A, Verma S. Maternal mortality: ten years retro $\neg$ spective study. JK Sci. 2010;12(3):134-6.

14.Bhosale A, Qureshi S, Nandanwar YS. Maternal mortality at a tertiary institute: a five year study. Bombay Hospital J. 2011; 53(2):189-92.
15.Ali MA, Babitha MC, Lokeshchandra HC, Sharma K D, Zehra M, Reddy S. A study of changing trends of maternal mortality at the tertiary care centre, MMC and RI Mysore, India. International Journal of Reproduction, Contraception, Obstetrics and Gynecology. 2015; 4(1): 239-42.

16.Satyasri YU, Isukapalli V, Thatavarthi P. Maternal Mortality Review in a Government Medical Hospital of North Coastal Andhra Pradesh based on FBMDR forms of NRHM: One Year Analysis. International Journal of Current Medical And Applied Sciences. 2015;5(3): 174-77.

\section{Pranjal Tamuli ${ }^{1}$, Hemkanta Sarma ${ }^{2}$, Abu Hasan Sarkar ${ }^{3}$ \\ ${ }^{1}$ State Program Officer, Non Communicable Disease, Assam; ${ }^{2} \mathrm{HOD}$, Dept of Obstetrics \& Gynaecology, Jorhat Medical College and Hospital, Assam; ${ }^{3}$ Assistant Professor, Dept. of Community Medicine Tomo Riba Institute of Health and Medical Sciences (TRIHMS) Naharlagun, Arunachal Pradesh.}

